\title{
Factors Influencing Usage of University Mobile Application Among University Students*
}

\author{
Khaled Salmen ALJAAIDI ${ }^{1}$, Omer Ali BAGAIS ${ }^{2}$, Raj Bahadur SHARMA ${ }^{3}$ \\ Received: August 01, 2020 Revised: September 06, 2020 Accepted: September 13, 2020
}

\begin{abstract}
This study investigates the factors influencing the usage of PSAU Mobile Application by the students at Prince Sattam bin Abdulaziz University (PSAU). This study used Technology Acceptance Model (TAM) as a framework to predict the factors influencing 67 students' usage of PSAU M-Application. The results of this study were consistent with the TAM framework in predicting the actual usage of the PSAU mobile application for academic activities. The results indicated a significantly positive association of the perceived ease-to-use with perceived usefulness, significantly positive associations of the perceived ease-to-use and the perceived usefulness with the attitude toward the usage of the PSAU's mobile application, a significantly positive association of the perceived usefulness with the behavioral intention toward the usage of the PSAU's mobile application, a significantly positive association of the students' attitude toward the usage of the PSAU's mobile application with the behavioral intention of using the application, and a significantly positive association of the behavioral intention with the actual usage of the PSAU's mobile application. The results of this study should be useful to educational policymakers at PSAU University and elsewhere, as there is an opportunity to enhance the existing technology or adopt new technologies for academic activities.
\end{abstract}

Keywords: Technology Acceptance Model, Mobile Application, University Students

JEL Classification Code: D83, M31, M39

\section{Introduction}

This study examines the factors that affect accounting student's actual usage of PSAU mobile applications for their academic studies. Prediction of these factors is made

\footnotetext{
*Acknowledgements:

This publication was supported by the Deanship of Scientific Research at Prince Sattam bin Abdulaziz University, Alkharj, Saudi Arabia.

${ }^{1}$ First Author and Corresponding Author. Assistant Professor, Accounting Department, College of Business Administration, Prince Sattam bin Abdulaziz University [Postal Address: Zayed bin Haretha Street, Al-Salam District, Al-Kharj, Al-Rayadh, 16244, Saudi Arabia] Email: k.aljaaidi@psau.edu.sa

2Lecturer, Accounting Department, College of Business Administration, Prince Sattam bin Abdulaziz University, Saudi Arabia. Email: o.bagais@psau.edu.sa

${ }^{3}$ Assistant Professor, Accounting Department, College of Business Administration, Prince Sattam bin Abdulaziz University, Saudi Arabia. Email: rbsharmaji@gmail.com

(c) Copyright: The Author(s)

This is an Open Access article distributed under the terms of the Creative Commons Attribution Non-Commercial License (https://creativecommons.org/licenses/by-nc/4.0/) which permits unrestricted non-commercial use, distribution, and reproduction in any medium, provided the original work is properly cited.
onrestricted non-commerial
}

using the Technology Acceptance Model (TAM) because it is a frequently used model among theoretical models that explain users' acceptance and application of technology (Davis, 1989; Davis et al., 1989). Extension of the TAM model was done by David et al. (1992) and Gefen et al. (2003). This model has found wide application in developed countries compared to developing ones, among them Arabic nations such as Saudi Arabia. According to TAM, the users of new technology and how they apply it are influenced by several factors. Based on a review of the existing TAM literature, limited research has been conducted on university students' use of mobile applications for academic purposes. To the researchers' best knowledge, no research has been conducted at PSAU to study the factors that affect the use of mobile applications in the institution. Consequently, to improve future acceptance and usage of PSAU mobile applications by students, understanding the factors that affect its use is necessary. Theoretically, the importance of this study is its contribution to expanding research on the academic use of mobile applications in institutions of higher learning. Further, since this study adds empirical data to a research area with inadequate data and studies conducted in 
the KSA setting, it is valuable (Bahaj et al., 2019) where this environment is characterized to have a paucity of research.

Through a systematic research, insight will be gained on the student, institutional, and academic factors in mobile application usage. Additionally, the review will provide an understanding of strategies to use to encourage the download and academic use of mobile applications by students. University administrators dealing with academic affairs can use the findings of this study to either improve the use of mobile applications by students or to come up with practical methods that they can use to encourage students to start using the applications. Also, the empirical data from this research will add evidence to the fields of technology and academics through prediction of acceptance of the M-application among PSAU students using the TAM model.

The remainder of the paper proceeds as follows. The next section briefly discusses the literature review and the development of the hypotheses. The third section describes the research design and methodology. The empirical results and discussions of the study are reported in the fourth section, while conclusions and implications are drawn in the final section.

\section{Literature Review and Hypothesis Development}

Currently, business operations, as well as academic activities, are affected by the use of technology. This is seen in the way that the introduction of the Internet has changed learning activities and dissemination of knowledge. An unprecedented growth rate is evident in higher learning, a trend resulting from the virtual conveyance of academic programs made possible by new and enabling technologies. Many scholars and academicians center debates and discussions around the application of technology in education since it influences education greatly, universities being the major service providers of online education. Seemingly, adopting technology in education is of great importance in the provision of updated information to students using methods that are better and more creative (Bahaj et al., 2019; Nedeva \& Zlatev, 2013; Khwaldeh et al., 2017; Kim-Soon et al., 2014). Presently, owing to the increase in mobile application availability, there has been a change in the computing experience. The development of mobile applications involves the formation of computer programs that are used in mobile devices, for example, smartphones and watches and tablets. The development of mobile applications is done for different operating systems, including Android, iOS, and Windows Mobile (Hamilton, 2019). The portability of mobile phones is the main advantage. The invention of mobile applications for smartphones gave a new approach to the service sector since the apps are developed to perform a given task. Widespread use of these apps has largely reduced time consumption as access to various goods and services is granted easily by using mobile devices (Bobbby, 2018).

Students tend to use mobile phones for everything, hence the name smartphone. The world is accessible, allowing students to gain any form of information wherever they are, reducing the need for library visitations and search for data, and making a mobile phone useful for various purposes such as this. Mobile applications grant the ease of access to information, each having unique features that allow it to offer its own set of services. Using traditional methods does not allow institutions to pay attention to students equally. The use of technology, however, makes this a possibility since institutional communication applications can be used to convey information to all students, for example, by informing them about new schedules, various meetings and conferences, and other social activities (Roy, 2017; Lee et al., 2016). Various leading companies and developers have developed educational apps that have influenced people around the world. These apps are valuable to both students and educationists because they provide easy and fast access to good-quality educational materials that were traditionally accessible only in libraries. The apps offer these services through e-Books, e-Library, and informative videos and games (Oza, 2017).

Prince Sattam bin Abdulaziz University has released a mobile application called PSAU, which is developed for various OS such as Android, iOS, and Windows Mobile. The application is free for downloading for Android device by accessing Google Play Store and for iOS device by accessing Apple App Store. The PSAU mobile application is a friendly applications designed to make it easier for students to access their academic services portal, email, e-learning portal, summer training system, GPA calculation, Gartner, students' GPA, students' employment system, IT services management system, students' information update, training center at community service, E-amend registration choices, students' activity services, Tawasol system, release letter, graduation certificate service, student status service, graduation projects, semester re-join service, transferring service, and academic recommendation for postgraduate study.

Technology Acceptance Model was developed and introduced by Davis (1989), as a theoretical extension of the Theory of Reasoned Action (TRA). This model is considered the most accepted model compared to other theoretical models that try to explain the relationship between user attitudes, contentment, and behavioral intention (Davis, 1989; Davis et al., 1989). The TRA (Fishbein \& Ajzen, 1975; Ajzen \& Fishbein, 1980) predicts acceptance by users depending on Perceived Usefulness (PU) and Perceived Ease of Use (PEU). The TAM builds on this idea. According to the TAM, PU and PEU dictate how users accept technology. Further, TAM indicates that PEU directly influences PU because a user will view technology as useful if it is easy 
Khaled Salmen ALJAAIDI, Omer Ali BAGAIS, Raj Bahadur SHARMA /

to use. TAM was later developed to predict the relationship between PU and PEU and attitude toward technology (AT), behavioral intention (BI) to technology use, and actual use (AU) of the technology. According to TAM, BI is directly influenced by both PU and AT as well as PU alone. BI also impacts the AU (Davis, Bagozzi \& Warshaw, 1989; Mallya \& Lakshminarayanan, 2017; Bahaj et al., 2019).

Thus, based on TAM as a framework for examining the factors influencing the usage of PSAU mobile application among accounting students from College of Business Administration at Prince Sattam bin Abdulaiziz PSAU and the extant research (e.g., Mallya \& lakshminarayanan, 2017; Ranta \& Mehra, 2015; Gajendra et al., 2014; Farahat, 2012; Dhume et al., 2012; Suki \& Ramayah, 2010; Park, 2009), the following testable hypotheses were developed:

H1: The perceived ease of using the PSAU mobile application has a direct influence on perceived usefulness of the application for the academic purposes.

H2: Perceived usefulness of the PSAU mobile application has a direct influence on the attitude to use the application for the academic purposes.

H3: Perceived ease of using the PSAU mobile application has a direct influence on the attitude to use the application for the academic purposes.

H4: Perceived usefulness of the PSUA mobile application has a direct influence on the behavioural intention toward using the application for the academic purposes.

H5: The attitude toward using the PSAUmobile application has a direct influence on the behavioural intention to use the application for the academic purposes.

H6: The behavioural intention toward using the PSAU mobile application has a direct influence on the actual usage of the application for the academic purposes.

\section{Research Methodology}

\subsection{Questionnaire Design}

This study is a quantitative method that was designed to examine the usage of PSAU mobile application by accounting students at Prince Sattam bin Abdulaziz University using Technology Acceptance Model (TAM). This study used the questionnaire as an appropriate data collection instrument for the purpose of answering the determined research questions: (1) What are the factors that predict accounting students' usage of PSAU's mobile application at Prince Sattam bin Abdulaziz University? And, (2) To what extent do the data fit to the TAM for the students in their usage of the PSAU's mobile application? The model of this study is adopted from the extant research (e.g., Mallya \& lakshminarayanan, 2017; Ranta \& Mehra, 2015; Gajendra et al., 2014; Farahat, 2012; Dhume et al., 2012; Suki \& Ramayah, 2010; Park, 2009)
The questionnaire consists of two different sections. The first section included subject information and the second subject included demographic information and questions related to the usage of the PSAU's mobile application for the academic purposes. To test the face validity and content validity, three subject experts duly reviewed the questionnaire before distributing it out. The final questionnaire is composed of 15 items that represent five constructs, namely, perceived usefulness (PU), perceived ease-to-use (PEU), attitude (AT), behavioral intention (BI), and actual use (AU).

\subsection{Instrument of Measurement}

\subsubsection{Demographic Information}

The demographic information in this study includes the gender, level of study, and age. As for the gender, a nominal value of " 1 " is assigned to male and " 2 " is assigned to female. With respect to level of study, a nominal value of " 1 " is assigned to freshmen, " 2 " is assigned to sophomore," 3" is assigned to junior" and " 4 " is assigned to senior. In terms of the age, a continuous value is assigned to the variable's measurement.

\subsubsection{Perceived Usefulness (PU)}

Perceived usefulness is one the concerns of this study. This variable is measured using a five-point Likert scale. The five-point Likert scale is ranging from 1 (strongly agree), indicating the highest level of agreement of the perceived PSAU mobile application as a useful technology, to 5 (strongly disagree), indicating to the lowest level of agreement of perceiving the PSAU mobile application as a useful tool. This variable consists of four items that are used to measure the respondents' level of agreement toward their perception of the usefulness of the PSAU's mobile application. This variable was subject to reliability test before it was used for further analysis. The four items constitute the perceived usefulness variable are as follows:

PU1: Using PSAU M-Application would enhance my effectiveness in learning

PU2: Using PSAU M-Application would improve my course performance

PU3: Using PSAU M-Application would improve my productivity in my course

PU4: I find PSAU M-Application useful for my study.

\subsubsection{Perceived Ease-to-Use (PEU)}

Perceived ease-to-use is one the concerns of this study. This variable is measured using a five-point Likert scale. The five-point Likert scale is ranging from 1 (strongly 
agree), indicating the highest level of agreement of the perceived PSAU mobile application as an easy to use technology, to 5 (strongly disagree), indicating to the lowest level of agreement of perceiving the PSAU mobile application as an easy to use tool. This variable consists of four items that are used to measure the respondents' level of agreement toward their perception of the easy-to-use of PSAU's mobile application. This variable was subject to reliability test before it was used for further analysis. The four items constitute the perceived ease-to-use variable are as follows:

PEU1: I find PSAU M-Application easy to use

PEU2: It is easy to navigate on PSAU M-Application

PEU3: It is would be easy for me to find the academicrelated information using PSAU M-Application

PEU4: My interaction with PSAU M-Application is clear and understandable.

\subsubsection{Attitude (AT)}

Attitude toward the PSAU mobile application is one the concerns of this study. This variable is measured using a fivepoint Likert scale. The five-point Likert scale is ranging from 1 (strongly agree), indicating the highest level of positive attitude toward the PSAU mobile application, to 5 (strongly disagree), indicating to the lowest level of positive attitude toward the PSAU mobile application. This variable consists of three items that are used to measure the respondents' attitude to toward the PSAU's mobile application. This variable was subject to reliability test before it was used for further analysis. The three items constitute the perceived ease-to-use variable are as follows:

AT1: It is a good idea to use PSAU M-Application for my study purpose

AT2: I like the idea to navigate on PSAU M-Application to be aware of the academic issues' updates

AT3: I have a positive attitude toward PSAU M-Application

\subsubsection{Behavioral Intention (BI)}

Behavioral intention toward the PSAU mobile application is one the concerns of this study. This variable is measured using a five-point Likert scale. The five-point Likert scale is ranging from 1 (strongly agree), indicating the highest level of intention to use the PSAU mobile application, to 5 (strongly disagree), indicating to the lowest level of intention to use the PSAU mobile application. This variable consists of three items that are used to measure the respondents' intention to use the PSAU's mobile application. This variable was subject to reliability test before it was used for further analysis. The three items constitute the perceived ease-to-use variable are as follows:

\section{BI1: I intend to frequently navigate on PSAU M-Application}

BI2: I intend to be a heavy user of PSAU M-Application

BI3: I intend to return to PSAU M-Application often.

\subsubsection{Actual Use (AU)}

Actual use of the PSAU mobile application is the final concern of this study. This variable is measured using a fivepoint Likert scale. The five-point Likert scale is ranging from 1 (strongly agree), indicating the highest level of the PSAU's mobile application usage, to 5 (strongly disagree), indicating to the lowest level of the PSAU's mobile application usage. This variable consists of one item that is used to measure the respondents' level of the PSAU's mobile application usage. The actual use item constitutes the actual use variable is as follows:

\section{AU I have no difficulty accessing and using PSAU M-Application.}

\subsection{Model Specification and Analysis}

This study applies the Technology Acceptance Model (TAM) to examine the accounting students' usage of PSAU mobile application. Multiple and Simple regressions were used to produce the results of this study. In particular, the TAM model can be expressed as follows:

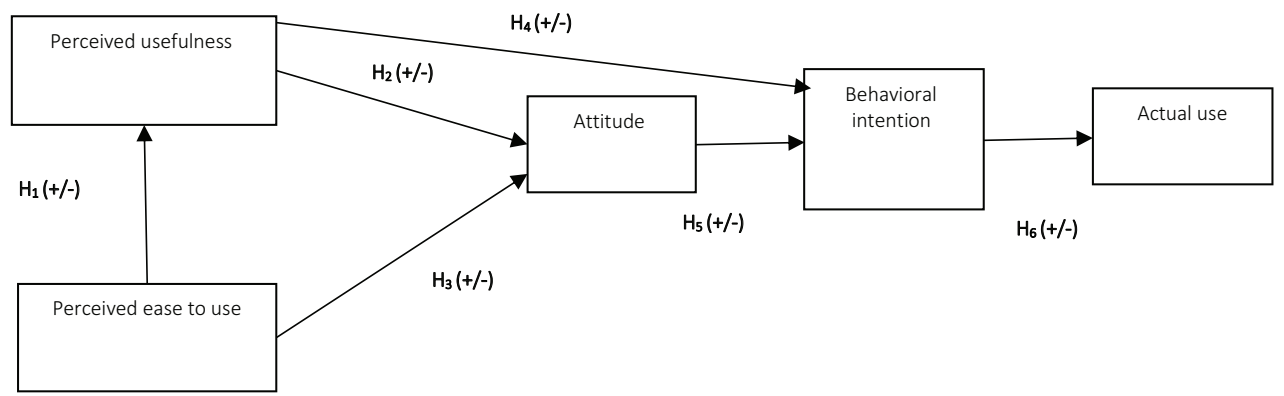

Figure 1: Research model of the study based on TAM (David, Bagozzi \& Warshaw, 1989) 
The analysis of data was completed using the SPSS version 20 of Windows. A descriptive statistical analysis using frequencies and percentages were used to describe the demographic information. The research question was addressed using multiple and simple regressions, Cronbach's Alpha and factor analysis.

\subsection{Data Collection}

The simple random sampling is used to distribute the questionnaire out to the students. This technique is used to select the right sample to represent the whole population. The sample includes the undergraduate accounting students in College of Business Administration at Prince Sattam bin Abdulaziz University for the academic year 2019-2020 in Saudi Arabia. The questionnaire was designed using the Google Forms technology in order to make it easier and faster to reach as many students as possible majoring in accounting discipline. The link of the questionnaire is distributed out to the students via emails or WhatsApp groups in collaboration with other faculty and students themselves. This process has yielded 67 usable questionnaires.

\section{Results and Interpretations}

\subsection{Sample Characteristics}

A total of 67 questionnaires were gathered from the survey. As shown in Table 1, the majority of the respondents $(71.6 \%)$ were male, $(35.8 \%)$ were senior students, and $(56.7 \%)$ were aged between 21 and 23 .

Table 2: Mean, Standard, Skewness and Kurtosis $(n=67)$

\subsection{Summary Statistics}

Descriptive statistics such as the mean, standard, skewness and kurtosis were calculated for each of the 15 items of the construct as illustrated in Table 2. As shown on Table 2, means for the items are between 4.06 and 3.12, and the standard deviation ranges between 1.21291 and .74840 . As for the normal distribution of the data, the values for skewness and kurtosis are calculated. The skewness and kurtosis values shown on Table 2 indicate that the data are normally distributed and considered acceptable because the values are between -1.96 and +1.96 as suggested by George and Mallery (2010) and Gravetter and Wallnau (2014).

Table 1. Demographic profile of respondents

\begin{tabular}{|l|c|c|}
\hline Demographic information & $\begin{array}{c}\text { Frequency } \\
(\boldsymbol{n}=\mathbf{6 7})\end{array}$ & Percent \% \\
\hline Gender & & \\
\hline Male & 48 & 73 \\
\hline Female & 19 & 27 \\
\hline Study level & & \\
\hline Freshmen & 10 & 14 \\
\hline Sophomore & 16 & 24 \\
\hline Junior & 17 & 26 \\
\hline Senior & 24 & 36 \\
\hline Age & & \\
\hline $18-20$ & 18 & 26 \\
\hline $21-23$ & 38 & 58 \\
\hline $24-26$ & 7 & 11 \\
\hline 26 and above & 4 & 06 \\
\hline
\end{tabular}

\begin{tabular}{|c|c|c|c|c|c|}
\hline Constructs & Items & Mean & Standard & Skewness & Kurtosis \\
\hline \multirow[t]{4}{*}{$\mathrm{PU}$} & PU1 & 3.60 & 1.04283 & $-.829-$ & .195 \\
\hline & PU2 & 3.40 & 1.01242 & $-.231-$ & -.023 \\
\hline & PU3 & 3.92 & .81601 & -.568 & .090 \\
\hline & PU4 & 3.69 & .74840 & $-.808-$ & .529 \\
\hline \multirow[t]{4}{*}{ PEU } & PEU1 & 3.62 & .94691 & $-.173-$ & $-.826-$ \\
\hline & PEU2 & 3.57 & .99952 & $-.487-$ & -.488 \\
\hline & PEU3 & 3.22 & .80024 & $-.224-$ & $-.024-$ \\
\hline & PEU4 & 3.54 & .81157 & $-1.123-$ & .747 \\
\hline \multirow[t]{3}{*}{ AT } & AT1 & 3.57 & .99427 & $-.657-$ & .388 \\
\hline & AT2 & 3.46 & 1.21291 & $-.639-$ & $-.328-$ \\
\hline & AT3 & 3.12 & .96027 & $-.581-$ & $-.031-$ \\
\hline \multirow[t]{3}{*}{$\mathrm{BI}$} & $\mathrm{BI} 1$ & 4.02 & 1.03020 & $-.728-$ & $-.268-$ \\
\hline & $\mathrm{BI} 2$ & 3.98 & 1.07406 & $-1.122-$ & .629 \\
\hline & $\mathrm{BI} 3$ & 4.06 & .90942 & $-.881-$ & .185 \\
\hline $\mathrm{AU}$ (1 item) & $\mathrm{AU}$ & 3.56 & .99427 & $-.657-$ & .388 \\
\hline
\end{tabular}




\subsection{Measurement Model}

To verify the construct validity of the items in the instrument, the confirmatory factor analysis (CFA) was used. Each item's reliability can be examined by calculating its factor loading on its corresponding latent variable. The loading of all items should be higher than 0.707 (Barclay et al., 1995). Others indicate that for established items, the factor loading for every item should be 0.6 or higher (Awang, 2014). Further, it is indicated that, if factor loading score is below 0.70, it is safer to consider its AVE which should be above 0.50 . The results of the CFA showed that the scales were valid for the factors under study because the factor loading fell above 0.70 except for PEU4 which is .616 as depicted in Table 3. In addition, the convergent validity was tested using the Average Variance Extracted (AVE). Hair et al. (2010) indicated that the AVE estimates should be 0.5 or greater in order to judge the adequate convergent validity. The results of AVE indicated to the existence of convergent validity among the constructs measured because the AVE estimates are all above 0.5 as exhibited in Table 3.
To test the reliability of each construct, Cronbach's Alpha was calculated. In order to determine whether the factor reliability is acceptable or not, the Cronbach's Alpha score should be at least 0.70 (Hair et al., 2010). The Cronbach's Alpha results indicated that the scales were reliable for the factors under study as showed in Table 3. In addition, the reliability was tested using the composite reliability (CR) that measures the degree to which the items are free from random error indicating to consistent results. The CR score should be at least 0.7 (Nunnally \& Bernstein, 1994). The CR results indicated that the scales were reliable for the factors under study as illustrated in Table 3.

Pearson correlation was calculated to determine the level of correlations between the variables as shown in Table 4 . As shown on Table 4, all the constructs were positively and significantly correlated with each other at level 0.01 . The correlation among the variables ranged from 0.511 to 0.832 at 0.01 level. In terms of conducting the multiple regression for the association of PU and PEU with AT, the correlation matrix verifies that no multicollinearity exists among the variables because the correlation score between the two independent variables is below 0.90 .

Table 3: Constructs' validity and reliability

\begin{tabular}{|c|c|c|c|c|c|}
\hline Constructs & Items & Factor loadings & Cronbach's alpha & CR & AVE \\
\hline \multirow[t]{4}{*}{$\mathrm{PU}$} & PU1 & .797 & .855 & 0.907 & 0.709 \\
\hline & PU2 & .887 & & & \\
\hline & PU3 & .823 & & & \\
\hline & PU4 & .858 & & & \\
\hline \multirow[t]{4}{*}{ PEU } & PEU1 & .839 & .774 & 0.854 & 0.598 \\
\hline & PEU2 & .864 & & & \\
\hline & PEU3 & .749 & & & \\
\hline & PEU4 & .616 & & & \\
\hline \multirow[t]{3}{*}{ AT } & AT1 & .838 & .808 & 0.889 & 0.727 \\
\hline & AT2 & .874 & & & \\
\hline & AT3 & .846 & & & \\
\hline \multirow[t]{3}{*}{$\mathrm{BI}$} & $\mathrm{BI} 1$ & .886 & .914 & 0.948 & 0.858 \\
\hline & $\mathrm{BI} 2$ & .946 & & & \\
\hline & $\mathrm{B} \mid 3$ & .946 & & & \\
\hline
\end{tabular}

Table 4: Correlation matrix $(n=67)$

\begin{tabular}{|c|c|c|c|c|c|}
\hline & PU & PEU & AT & $\mathrm{BI}$ & $A U$ \\
\hline PU & 1 & & & & \\
\hline PEU & $.741^{\text {** }}$ & 1 & & & \\
\hline AT & $.737^{* *}$ & $.659^{* *}$ & 1 & & \\
\hline $\mathrm{BI}$ & $.647^{* *}$ & $.513^{* *}$ & $.732^{\star \star}$ & 1 & \\
\hline $\mathrm{AU}$ & $.765^{\star *}$ & $.511^{* *}$ & $.832^{\star \star}$ & $.686^{* \star}$ & 1 \\
\hline
\end{tabular}


Khaled Salmen ALJAAIDI, Omer Ali BAGAIS, Raj Bahadur SHARMA /

Table 5: Summary of hypotheses tests

\begin{tabular}{|c|c|c|c|c|c|c|c|c|c|}
\hline \multicolumn{4}{|c|}{ Hypotheses } & $R^{2}$ & $\begin{array}{c}\text { Adjusted } \\
R^{2}\end{array}$ & $\begin{array}{l}\text { Standardized } \\
\text { coefficients } \beta\end{array}$ & $F$ & Sig. & Results \\
\hline $\mathrm{H}_{1}$ & PEU & $\rightarrow$ & $\mathrm{PU}$ & .549 & .542 & .741 & 76.838 & .000 & Supported \\
\hline $\mathrm{H}_{2}$ & PU & \multirow{2}{*}{$\rightarrow$} & \multirow{2}{*}{ AT } & \multirow{2}{*}{.571} & \multirow{2}{*}{.557} & .551 & \multirow{2}{*}{41.235} & .000 & Supported \\
\hline $\mathrm{H}_{3}$ & PEU & & & & & .250 & & .048 & Supported \\
\hline $\mathrm{H}_{4}$ & $\mathrm{PU}$ & $\rightarrow$ & $\mathrm{BI}$ & .419 & .409 & .647 & 45.365 & .000 & Supported \\
\hline $\mathrm{H}_{5}$ & AT & $\rightarrow$ & $\mathrm{BI}$ & .537 & .529 & .732 & 72.932 & .000 & Supported \\
\hline $\mathrm{H}_{6}$ & $\mathrm{BI}$ & $\rightarrow$ & $A U$ & .471 & .463 & .686 & 57.047 & .000 & Supported \\
\hline
\end{tabular}

\subsection{Hypotheses Testing}

To test the hypotheses developed by this study, multiple and simple regressions were conducted. The multiple regression analysis was conducted to examine the association of PU, PEU and AT. As for the associations of PU with PEU, PU with BI, AT with BI, and BI with AU, the simple regression analysis was conducted to test each association as shown in Table 5.

As depicted on Table 5, perceived usefulness of the PSAU mobile application for academic purposes was predicted by perceived ease-to-use $(\beta=0.741, p<0.001)$, resulting in $R 2$ of 0.549 , which means that PEU accounted for a $54.9 \%$ variance in PU. This indicates that the students' perceived ease-of-use influences positively the perceived usefulness of the PSAU mobile application. Therefore, H1 is supported. In addition, the R2 for the association of PEU and PU with AT was 0.571 , indicating that the students' PEU and PU explain $57.1 \%$ of the variance in the students' attitude toward the PSAU mobile application. This result shows that both PEU $(\beta=0.250, \mathrm{p}<$ $0.05)$ and $\mathrm{PU}(\beta=0.551, \mathrm{p}<0.001)$ are significantly and positively influencing the students' attitudes toward the usage of PSAU mobile application. Thus, $\mathrm{H} 2$ and $\mathrm{H} 3$ are supported.

Table 5 also shows that perceived usefulness of the PSAU mobile application for academic purposes influences the behavioral intention BI toward the usage of PSUA mobile application $(\beta=0.647, p<0.001)$, resulting in $\mathrm{R} 2$ of 0.419 , which means that PU accounted for a $41.9 \%$ variance in BI. This indicates that the students' perceived usefulness of the PSAU mobile application is associated positively with their behavioral intention toward the usage of the PSAU mobile application. Therefore, $\mathrm{H} 4$ is supported. Further, the behavioral intention BI toward the usage of the PSAU mobile application for academic purposes was predicted by the attitude toward the usage of the application $(\beta=0.732, p<0.001)$, resulting in R2 of 0.537 , which means that AT accounted for a $53.7 \%$ variance in BI. This indicates that the students' attitude toward the PSAU mobile application influences positively their behavioral intention in using the PSAU mobile application. Therefore, H5 is supported. Moreover, Table 5 shows that the actual usage AU of the PSAU mobile application for academic purposes was predicted by the behavioral intention toward the usage of the application $(\beta=0.686, p<0.001)$, resulting in R2 of 0.463 , which means that BI accounted for a $46.3 \%$ variance in AU. This indicates that the students' actual usage of the PSAU mobile application is positively associated with the behavioral intention. Therefore, H6 is supported. Specifically, the results exhibited by Table 5 are, in general, consistent with previous studies used the TAM framework (e.g., Mallya \& lakshminarayanan, 2017; Ranta \& Mehra, 2015; Gajendra et al., 2014; Farahat, 2012; Dhume et al., 2012; Suki \& Ramayah, 2010; Park, 2009).

\section{Conclusion}

The purposes of this study were to examine the factors that predict 67 accounting students' usage of PSAU's mobile application at Prince Sattam bin Abdulaziz University, and to report the extent to which the data fit to the TAM for the students in their usage of the PSAU's mobile application for the academic year 2019-2020. The findings of this study were consistent with the TAM framework in predicting the actual usage of the PSAU mobile application for academic activities. The results indicated that: (1) a significantly positive association of the perceived ease-to-use with perceived usefulness, (2) significantly positive associations of the perceived ease-to-use and the perceived usefulness with the attitude toward the usage of the PSAU's mobile application, (3) a significantly positive association of the perceived usefulness with the behavioral intention toward the usage of the PSAU's mobile application, (4) a significantly positive association of the students' attitude toward the usage of the PSAU's mobile application with the behavioral intention of using the application, and (5) a significantly positive association of the behavioral intention with the actual usage of the PSAU's mobile application. The findings of this study confirm that the actual usage of the PSAU's mobile application is determined by the four constructs suggested by TAM model. This implies that the existing TAM framework is able to predict what makes students accept the usage of technology for their academic activities. 
Albeit this research reported meaningful results explaining the factors influence the actual usage of technology among students in higher educational institutions, it is still subject to a limitation in which future line of research can investigate it. The sample size of this study consists of 67 accounting students which is considered a small sample size. In this regard, there is an opportunity for the future research to consider using a large sample of accounting students and involving different disciplines as well with the College of Business Administration such as management, finance, law, human resource, and management information system. The future research can also consider a sample of students from other colleges such medical and engineering colleges.

\section{References}

Ajzen I., \& Fishbein, M. (1980). Understanding Attitudes and Predicting Social Behavior. Englewood Cliffs, NJ: Prentice Hall.

Awang, Z. (2014). A handbook on SEM for academicians and practitioners: the step by step practical guides for the beginners. Bandar Baru Bangi, MPWS Rich Resources.

Bahaj, S., Aljaaidi, K., \& Ahmed, T. (2019). Using TAM model to empirically examine students' attitudes toward e-services in college of business administration. Management Science Letters, 9(5), 651-660.

Barclay, D. W., Higgins, C., \& Thompson, R. (1995). The partial least squares (PLS) approach to causal modeling: Personal computer adaptation and use as an illustration. Technology Studies, 2(2), 285-309.

Bobbby, R. (2018). Importance of mobile apps in todays' world. Retrieved July 13, 2020 from: https://yourstory.com/mystory/ importance-of-mobile-apps-in-todays-world-08ou5wgu7g

Davis, F. (1989). Perceived usefulness, perceived ease of use, and user acceptance of information technology. MIS Quarterly, 13(3), 319-340.

Davis, F., Bagozzi, R., \& Warshaw, P. (1989). User acceptance of computer technology: a comparison of two theoretical models. Management Science, 35(8), 982-1003.

Dhume, S. M., Pattanshetti, M. Y., Kamble, S. S., \& Prasad, T. (2012). Adoption of social media by business education students: Application of Technology Acceptance Model (TAM). In: 2012 IEEE International Conference on Technology Enhanced Education (ICTEE) (pp. 1-10). IEEE.

Farahat, T. (2012). Applying the technology acceptance model to online learning in the Egyptian universities. Procedia-Social and Behavioral Sciences, 64, 95-104.

Fishbein, M., \& Ajzen, I. (1975). Belief, attitude, intention and behaviour: An introduction to theory and research. Reading, MA: Addison-Wesley.

Gefen, D. (2003). TAM or just plain habit: A look at experienced online shoppers. Journal of Organizational and End User Computing, 15(3), 1-13.
Hair, J. F., Anderson, R. E., Babin, B. J., \& Black, W. C. (2010). Multivariate data analysis (Vol. 7). New York, NY: Pearson.

Hamilton, E. (2019). Why mobile apps are important for your business? Retrieved July 13, 2020 from: https://www. techtimes.com/brandspin/242588/20190504/why-mobileapps-are-important- for-your-business.htm

Khwaldeh, S. M., Al-Hadid, I., \& Masadeh, R. E. (2017). The association between e-services web portals information quality and ICT competence in the Jordanian universities. Asian Social Science, 13(3), 156.

Kim-Soon, N., Rahman, A., \& Ahmed, M. (2014). E-service quality in higher education and frequency of use of the service. International Education Studies, 7(3). DOI:10.5539/ies.v7n3p1

Lee, J. W., Becker, K., \& Potluri, R. M. (2016). Antecedents of Corporate Adoption of Social Media and the Role of the Technology Acceptance Model in the Path. Journal of Asian Finance, Economics and Business, 3(2), 67-76. https://doi. org/10.13106/jafeb.2016.vol3.no2.67.

Mallya, J., \& Lakshminarayanan, S. (2017). Factors Influencing Usage of Internet for Academic Purposes Using Technology Acceptance Model. Journal of Library \& Information Technology, 37(2).

Nedeva, V., \& Zlatev, Z. (2013). Quality of The Services Provided by A University Web Portal. Applied Researches in Technics, Technologies and Education, 1(3), 173-180.

Nunnally, J. C., \& Bernstein, I. H. (1994). Psychometric theory (3rd ed.). New York, NY: McGraw Hill

Oza, H. (2017). The importance of mobile applications in everyday life. Retrieved July 13, 2020 from: https://www. hyperlinkinfosystem.com/blog/the-importance-of-mobileapplications-in-everyday-life\#

Park, S. Y. (2009). An analysis of the technology acceptance model in understanding university students' behavioral intention to use e-learning. Journal of Educational Technology \& Society, 12(3), 150-162.

Ratna, P. A., \& Mehra, S. (2015). Exploring the acceptance for elearning using technology acceptance model among university students in India. International Journal of Process Management and Benchmarking, 5(2), 194-210.

Ratna, P. A., \& Mehra, S. (2015). Exploring the acceptance for elearning using technology acceptance model among university students in India. International Journal of Process Management and Benchmarking, 5(2), 194-210.

Roy, S. (2017). 5 benefits of using mobile apps in education. Retrieved July 13, 2020 from: https://elearningindustry.com/ mobile-apps-in-education-5-benefits

Sharma, G., Shakya, S., \& Kharel, P. (2014). Technology acceptance perspectives on user satisfaction and trust of e-government adoption. JApSc, 14(9), 860-872.

Suki, N. M., \& Ramayah, T. (2010). User acceptance of the e-government services in Malaysia: structural equation modelling approach. Interdisciplinary Journal of Information, Knowledge, and Management, 5(1), 395-413. 